
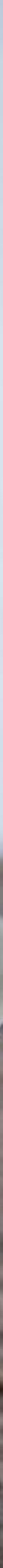

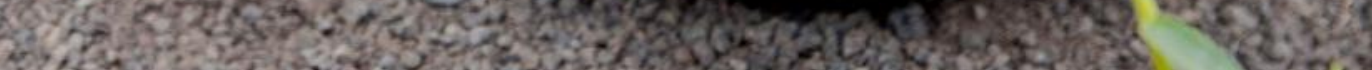

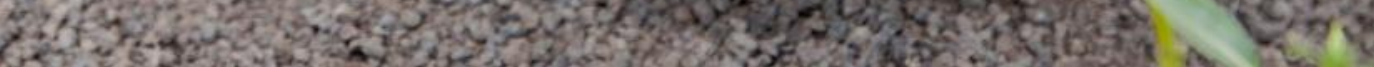
630 s

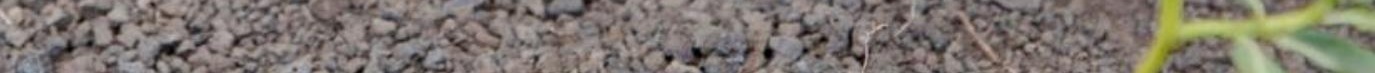

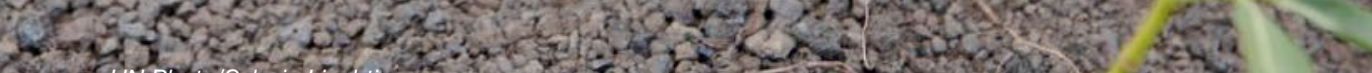

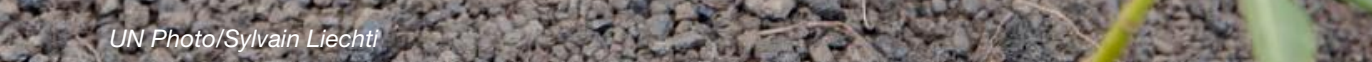

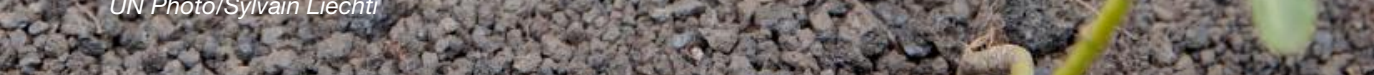

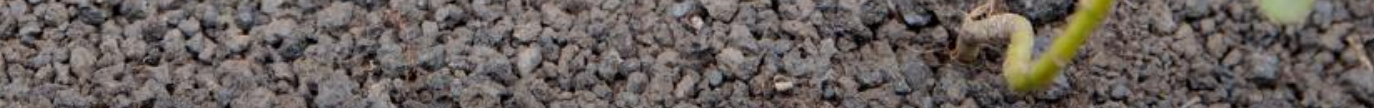

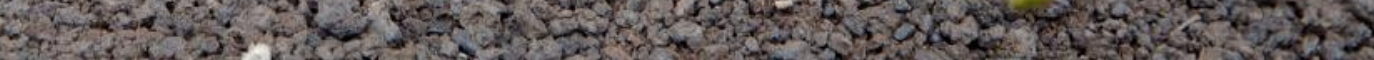

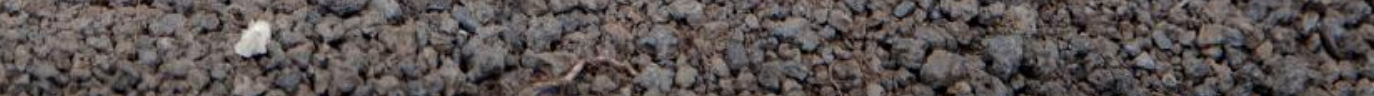

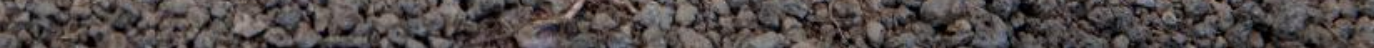




\section{CHILD SOLDIERS IN THE DEMOCRATIC REPUBLIC OF CONGO: REVISITING 'REINTEGRATION' THROUGH A PSYCHO-SOCIAL FRAMEWORK}

\section{By Arpita Mitra}

Advanced Master's graduate from the Geneva

Academy of International Humanitarian Law

and Human Rights (Transitional Justice)

and the University of Oxford (Criminology)

\section{ABSTRACT}

The paper assesses 'reintegration' mechanisms implemented for child soldiers in the Democratic Republic of Congo (DRC) in the overall Disarmament-Demobilisation-Reintegration (DDR) programme. It re-visits the 'macro-level success' claimed by DDR mechanisms in DRC internationally and focuses on evaluation strategies at the 'micro-level' implementation of the said objectives. The paper advances a psycho-social assessment of reintegration of child soldiers considering their complex identities as 'victim-perpetrator-bystander'. Identifying the gaps between individual experiences of war trauma (psychological breakdown) and community reintegration (social reintegration, discrimination, and stigma), the paper conceptualises reintegration measures vis-à-vis children's psycho-social needs and greater community involvement. 


\section{INTRODUCTION - 'MACRO-LEVEL SUCCESS TO MICRO-LEVEL GAPS'}

On 14 March 2012, the International Criminal Court (ICC) sentenced a Congolese warlord to 14 years for the war crimes of 'enlisting and conscripting children under the age of 15 years and using them to participate actively in hostilities (child soldiers)'. The Prosecutor $v$ Thomas Lubanga Dyilo ('Thomas Lubanga') (2012) became the first sentence handed down by the ICC, setting a precedent vis-à-vis the recruitment of child soldiers. Five years later, in December 2017, the Court determined Thomas Lubanga's financial liability to be a total of US $\$ 10$ million for providing reparations to the victims - the highest compensation judges at the Court have ever placed on an individual. ${ }^{1}$

This landmark ruling reflects the grave violation concerning 'children associated with fighting force' (or 'CAFF') both in terms of the act of child recruitment and the wide range of associated purposes including, but not limited to, sexual exploitation, spying, bearing munitions and performance in frontline combat units. ${ }^{2}$ The judgment serves a twin-purpose - to 'acknowledge' the harms systematically committed on children in the DRC and equally focus on provisions for repairing the harms that align with, ${ }^{3}$ among others, medical and psychological treatment, although what this treatment should entail remains ambiguous.

At the regional and national level in the Democratic Republic of Congo (DRC) and the Great Lakes region, reintegration of ex-combatants, including child soldiers, was undertaken by the Multi-Country Demobilisation and Reintegration Programme (MDRP) between 2002 and 2009. The Disarmament Demobilisation and Reintegration (DDR) programme involved seven countries, ${ }^{4}$ a funding of USD 450 million, and demobilisation of approximately 300,000 ex-combatants, making it largest programme of such a mandate in the world. ${ }^{5}$ Despite the acclaimed macro-level success, reintegration measures were challenging to achieve. Within the context of operational delays and prolonged emphasis on disarmament and demobilisation, minimal time was reserved for the objective and preparation of reintegration, more specifically with regards to training and execution of reintegration activities. ${ }^{6}$ Child-specific reintegration

1 Reuters Staff, "Congo child soldiers awarded $\$ 10$ million compensation in landmark ruling”, Reuters, December 15, 2017, https://www.reuters.com/article/us-warcrimes-congo/congo-child-soldiersawarded-10-million-compensation-in-landmark-ruling-idUSKBN1E9110.

2 Human Rights Council 37/47, Annual report of the Special Representative of the Secretary-General for Children and Armed Conflict, A/HRC/37/47, January 8, 2018, www.undocs.org/A/HRC/37/47 [hereinafter Human Rights Council 37/47].

3 Human Rights Council 37/47.

4 The seven countries involved in the conflict on the territory of DRC - Republic of Congo, Central African Republic, Burundi, Uganda, DRC, Rwanda, Angola.

5 Andre Kollin, "DDR in the Democratic Republic of Congo", Peace Direct, November 2011, 1-4 [hereinafter Andre Kollin, "DDR in the Democratic Republic of Congo" 2011].

6 Development Alternative Inc (DAl), "Independent Evaluation of Special Projects for Child Soldiers 
incorporates a range of activities, these included - psycho-social support, restoration of basic services of schooling, healthcare and vocational training - all of which are adapted to the specific and differential needs of children as returnees from the conflict. Investing minimal time in reintegration obstructs the long-term development of these activities, including the sustained involvement of community members as well as the scope for monitoring and follow-up programmes by DDR practitioners and social workers. ${ }^{7}$

In the DRC, despite instituting a DDR programme for approximately 300,000 ex-combatants, 'reintegration' could only achieve $58 \%$ of the estimated target. ${ }^{8}$ In particular, the situation concerning the reintegration of child soldiers faced more difficulties. The MDRP consisted of four key components, ${ }^{9}$ one of which was the 'Special Projects' component responsible for the DDR mechanisms for child soldiers. Initially, the MDRP-funded DDR process for child soldiers targeted an intervention for approximately 30,000 ex-combatants. However, out of a total of 12,511 child soldiers who were reported to have become part of the reintegration efforts, only 604 of them completed the entire process. In other words, the Special Projects component could achieve only $2.9 \%$ of the overall target before the program elapsed. ${ }^{10}$ Additionally, the Commission Nationale de Démobilisation et Réintégration (CONADER), the agency set up to manage the needs of child soldiers in DRC before a national DDR Programme could be instituted, was widely critiqued on grounds of its limited capacity to effectively coordinate a comprehensive DDR mechanism due to its weak institutional foundations, shortage of technical expertise, lack of decentralisation, concerns around internal corruption and the overall inadequacy in its supervisory and coordination roles for child-centred DDR. ${ }^{11}$

The DDR programme in DRC goes to demonstrate that acclaimed macro-level achievements do not always translate to ground realities,, calling for needs-assessment with regards to children's individual experiences and community interactions. This paper assesses the 'reintegration' component of the overall DDR programme for former child soldiers in DRC. It sheds light on some of the psycho-social harms experienced by child soldiers - a neglect

in the Democratic Republic of Congo, Final Report Presented to The World Bank's Multi-country Demobilization and Reintegration Program (MDRP)", February 5, 2007:1-18, http://www.crin.org/ en/docs/Congo\%20child\%20D\%20and\%20R\%20evaluation.pdf [hereinafter DAl "Independent Evaluation of Special Projects", 2007].

7 IDDRS 5.30 Children and DDR.

8 Andre Kollin, "DDR in the Democratic Republic of Congo", 2011, 4.

9 These included - the Demobilisation and Reintegration Programme (DRPs), special projects, regional activities and programme management. The Special Projects was a coordinated effort of different organisations such Save the Children, UNICEF and the Belgian Red Cross.

10 DAl "Independent Evaluation of Special Projects", 2007, 17

11 DAl "Independent Evaluation of Special Projects", 2007, 4 
of which has impeded the process of reintegration. Using Betancourt's approach, ${ }^{12}$ the paper examines the gap between children's individual war exposure and psychological breakdown and the post-conflict experiences concerning stigma and community perceptions that determine their psycho-social reintegration. The paper suggests that bridging this disjunction requires an integrated approach, community involvement, but most importantly, drawing a link between national reparations measures and provisions of reintegration under the DDR within a psycho-social framework.

\section{WHERE DID DDR IN DRC GO WRONG?}

The DDR process largely functioned through a quasi-official manner, including situations such as individual commanders bringing children to a transit centre or contacting a relevant organisation. ${ }^{13}$ Yet, there continued to remain certain conceptual and procedural ambiguities, some of which are described below.

\section{a. Normative Definitions of $D D^{\prime} R$ '}

Recognising the involvement of multiple parties both within and outside the country, the DDR programme in DRC is often referred to as DDRRR, or disarmament, demobilisation, reintegration, resettlement, or repatriation. In addition to traditional DDR approaches, the DDRRR refers to repatriation and resettlement of foreign fighters back to their country of origin. ${ }^{14}$ At the same time, given the difference in linguistic usage, there is a demarcation made between 'reinsertion' and 'reintegration' of former combatants, including child soldiers. Articles 71 and 73 of the Law No. 09/001 (adopted as on 10 January 2009) restates the State's responsibility in ensuring child protection in 'exceptional situations' 15 and the demarcation between 'reinsertion' (...et sa reinsertion en famille ou en communauté) and 'readaptation' (...'réadaptation et al réinsertion') respectively. Reinsertion was often conceptualised as a phase preceding reintegration of child soldiers - a 'transitional safety net' - unlike

12 Theresa Betancourt et al. "Past horrors, present struggles: The role of stigma in the association between war experiences and psychosocial adjustment among former child soldiers in Sierra Leone”, Social Science and Medicine, Vol.70, Issue 1, January 2010, 17-26, 10.1016/j. socscimed.2009.09.038 [hereinafter Theresa Betancourt "Past horrors, present struggles", 2010].

13 Beth Verhey, "Going Home: Demobilising and reintegrating child soldiers in the Democratic Republic of Congo", Save the Children, 2003, 1-13, https://resourcecentre.savethechildren.net/library/ going-home-demobilising-and-reintegrating-child-soldiers-democratic-republic-congo [hereinafter Beth Verhey "Going Home", 2003].

14 Beth Verhey, "Going Home", 2003, 10.

15 LAW NO 09/001 Concerning Child Protection January 10, 2009, Democratic Republic of Congo, Journal Officiel. As per Chapter I General Provisions, Point 5, "Children in exceptional situations: children in situations of armed conflict, tensions or civil unrest, natural disasters or significant and prolonged deterioration of socio-economic conditions". It provides for "exceptional protection", by which it prohibits the enlisting or using of children in the armed forces or armed groups. 
long-term re-adaptation, which was a 'life-long' endeavour. ${ }^{16}$ It was conceptualised as a child's participation in the transit centre or camp for a period roughly between 3-6 months, wherein they received psycho-social counselling. ${ }^{17}$ Further, reinsertion measures were often considered akin to 'rehabilitation' - a process whereby child soldiers were prepared to adjust to civilian life 'before' they were facilitated into the process of reintegration.

In practice, the two concepts of 'reinsertion' and 're-adaptation' were often used synonymously, and interchangeably, even though there existed a demarcation of the different tasks within each. ${ }^{18}$ Consequently, evaluation teams and stakeholders were met with confusion 'over the normative definitions and objectives' with regards to reintegration. ${ }^{19}$ This lack of clarity had negative implications with regards to sequencing different activities that concern transit centre-based support, short-term reinsertion support, and long-term reintegration, and the specific psycho-social needs of children at each stage therein.

\section{b. Eligibility and Exclusion in the DDR Framework}

Two strategies were conceptualised in response to the weaknesses and mismanagement within DDR programmes, especially with regards to reintegration. The principle of 'one weapon, one combatant' was executed in the second and third phases (more specifically in Ituri, Phase III) of the nationally-guided DDR process. ${ }^{20}$ Eligibility under the national DDR programme was determined as per three factors: (a) DRC nationality, (b) ability to prove membership in an armed group recognised by the government and (c) either armed or in possession of a certificate of disarmament. ${ }^{21}$ Contrary to expectations, the 'one weapon one combatant' principle restricted the number of eligible persons for the DDR programme.

16 Andre Kollin, "DDR in the Democratic Republic of Congo", 2011, 6.

17 Lt. Col. Donatien Nduwimana, "Reintegration of Child Soldiers in Eastern Democratic Republic of Congo: Challenges and Prospects", The International Peace Support Training Centre Nairobi, Kenya, Occasional Paper Series 4 No. 2, (2013:5) https://www.icc-cpi.int/RelatedRecords/CR2017_04712. PDF.

18 Robert Muggah, et al, "The Long Shadow of War: Prospects for Disarmament, Demobilisation and Reintegration in the Republic of Congo: $A$ Joint Independent Evaluation for the European Commission, UNDP, and the MDRP Secretariat" February 13 - March, 6, 2003: 1-9 [hereinafter Robert Muggah, et al, "The Long Shadow of War", 2003].

19 Robert Muggah, et al, "The Long Shadow of War", 2003, 9.

20 Joanne Richards, "Demobilization in the DRC Armed Groups and the Role of Organizational Control", Small Arms Survey Issue Brief, Brief No.1, 2013, 5, <http://www.smallarmssurvey.org/ fileadmin/docs/G-Issue-briefs/SAS-AA-IB1-DDR-in-the-DRC.pdf> [hereinafter Joanne Richards, "Demobilization in the DRC Armed Groups", 2013].

21 Joanne Richards, "Demobilization in the DRC Armed Groups", 2013, 5. 
First, for many armed groups in DRC, specifically among the Mai-Mai, the 'ratio of combatants' was disproportionate to the number of weapons; these weapons often being less and shared within an armed group. ${ }^{22}$ This impacted child soldiers' access to government-led DDR provisions. ${ }^{23}$ Additionally, the principle lacked consistency with the international understanding of a 'child associated with an armed group' in varying capacities such as cooks, porters, messengers, spies, and for sexual purposes. ${ }^{24}$

\section{Contrary to expectations, the 'one weapon one combatant' principle restricted the number of eligible persons for the DDR programme.}

Second, the identification of young girls in armed groups remained fairly difficult in DDR programmes. Across DRC, young girls involved with the armed forces have been referred to as 'shadow armies' for continuing to serve as 'servants, messengers, porters, cooks and sexual slaves or wives'. ${ }^{25}$ As a result, they often fail to meet the one weapon one combatant principle and their involvement in a range of other activities within armed groups is rendered invisible. In fact, DDR programmes in DRC record registration of only $2.6 \%$ female combatants among the total share of ex-combatants. ${ }^{26}$

Additionally, reintegration of female participants was heavily influenced by the community perceptions. Social ostracisation and exclusion took the form of everyday interactions, wherein, for instance, female soldiers were not allowed to associate with other girls in the neighbourhood and were labelled as 'bush wives. ${ }^{27}$ In DRC, reintegration of female soldiers and participants in armed conflict remained far more complex, due to a range of factors.

22 Joanne Richards, "Demobilization in the DRC Armed Groups", 2013, 7. "A former MaiMai Simba captain reported that a group of 30 combatants might have had only ten firearms between them."

23 Joanne Richards, "Demobilization in the DRC Armed Groups", 2013, 9. "A former child combatant from Goma explained that: Since we were demobilized we have received nothing. The ones who received something are those who handed in weapons. We are considered as if we are not demobilized."

24 UNICEF The Paris Principles: Principles and Guidelines on Children Associated With Armed Forces or Armed Groups, The United Nations, 2007 - 2.1 of the Paris Principles reads - "A child associated with an armed force or armed group" refers to any person below 18 years of age who is or who has been recruited or used by an armed force or armed group in any capacity, including but not limited to children, boys and girls, used as fighters, cooks, porters, messengers, spies or for sexual purposes. It does not only refer to a child who is taking or has taken a direct part in hostilities."

25 Elisabeth Schauer and Thomas Elbert, "The Psychological Impact of Child Soldiering", ed. E. Martz (Springer), (2010, 311-15) [hereinafter Elisabeth Schauer et al. "The Psychological Impact of Child Soldiering", 2010].

26 Andre Kollin, "DDR in the Democratic Republic of Congo", 2011, 11.

27 Sandra Olsson 'Hear the Voices of Congo's Girl Child Soldiers', IRIN NEWS, https://www.irinnews. org/opinion/2017/06/19/hear-voices-congo\%E2\%80\%99s-girl-child-soldiers. 
Such factors include, the fear of being easily identified by the community, the suspicion and stigma attached to their identities, association of shame, dishonour, 'loss of value' that these girls bring upon themselves, their family and community by virtue of their association with the fighting forces and assumption of having experienced sexual abuse and involvement with multiple sexual partners. ${ }^{28}$

Stigma was part of young girls' individual and inter-personal experiences. To begin with, the risks of experiencing conflict-related violence, including rape, abduction, sexual slavery targeted against women, and the roles performed by female combatants within armed groups was often a direct manifestation of the gendered values embedded in the society and community interactions. Additionally, the fear of negative community perceptions upon return shaped individual stigma in the form of internalised shame and self-inflicted denial. In fact, rather than being recognised as CAFF and qualify for processes of demobilisation and reintegration, girls often regarded their association with armed factions in the form of social roles such as 'wives or cooks'. ${ }^{29}$ In this regard, individual characteristics of stigma must be understood within the social context and as a consequence of the social responses to the stigmatised individual. ${ }^{30}$ Ultimately, the social context impacts children's long-term psycho-social adjustment and has differential impact based on one's gender.

\section{II. 'VICTIM-PERPETRATOR' DIVIDE, COMPETING VICTIMHOOD AND DETERMINATION OF BENEFICIARIES}

There continues to remain a dearth of empirical data for assessing the mental health and psycho-social impact of the armed conflict on child soldiers as 'perpetrators' of violent acts. ${ }^{31}$ Practitioners face a dilemma in classifying child soldiers in the determination and allocation of beneficiaries, which are otherwise provided for 'victims' of an armed conflict. The neat 'victim-perpetrator' divide, often conceptualised for heuristic purposes, fails to account for a direct proportionality between cumulative experiences of committing violence and exposure to mental health concerns such as post-traumatic stress disorder (PTSD). ${ }^{32}$

Because of their age and lower ranks in armed groups, former child soldiers are reported to commit more atrocities during the conflict, both in quantity and gravity of violence,

28 Save the Children, "Forgotten Casualties of War: Girls in Armed Conflict", Save the Children UK, https://resourcecentre.savethechildren.net/node/2717/pdf/2717.pdf 1-30.

29 DAl "Independent Evaluation of Special Projects", 2007, 20.

30 Theresa Betancourt 'Past horrors, present struggles', 2010.

31 Anna Maedl, et al. "Psychological Rehabilitation of Ex-combatants in Non-Western, Post-conflict Settings" ed. E. Martz (Springer), (2010, 177-181) [hereinafter Anna Maedl, et al. "Psychological Rehabilitation of Ex-combatants", 2010]. 
than some of the adult former combatants. ${ }^{33}$ Equally, mental health experts account for a 'building-block effect' due to child soldiers' direct exposure to violence. Repeated exposure to different types of traumatic stressors accumulate and heighten their risk of developing trauma-related disorders that subject them to psychological vulnerabilities. ${ }^{34}$ Despite their return and family reunification, former child soldiers are reported to experience anxiety, stress, and PTSD, including 'repetitive-compulsive' behaviour. Due to this behaviour, children are prone to re-enact an event of trauma, either in the form of memory (flashback, nightmares) or actions which are violent in nature. ${ }^{35}$ Therefore, the risks of former child soldiers committing violence upon their return are not only enhanced; they also stifle the process of community acceptance and the broader social understanding of the trauma-inducing causes behind such individual behaviour. ${ }^{36}$ Thus, owing to the tensions in classifying a child soldier's identity as a victim or perpetrator, as well as accounting for some of these community perceptions, DDR programmes are often critiqued on grounds of 'rewarding bad behaviour. ${ }^{37}$ These perceptions can be understood in light of the broader context of the conflict.

33 Katharin Hermenau, et al., "Growing up in armed groups: trauma and aggression among child soldiers in DR Congo", European Journal of Psychotraumatology, November 6, 2013, 4: 21408 - http://dx.doi.org/10.3402/ejpt.v4i0.21408 [hereinafter "Katharin Hermenau, et al., "Growing up in armed groups" 2013] states that "...child soldiers in the conflict in the eastern DRC begin their military career from the bottom, whereas adult combatants and soldiers start with higher ranks depending on their educational background or age. Frequently, child soldiers have to execute the most dangerous and gruesome tasks in which they experience and perpetrate significant amounts of violence".

34 Katharin Hermenau, et al., "Growing up in armed groups”, 2013.

35 Anne Whitehead, "Trauma Fiction”, Edinburgh: Edinburgh University Press, 2004, 119, 153-140 [hereinafter Anne Whitehead "Trauma Fiction" 2004]. Repetition-compulsion is a Freudian concept referring to a person who repeats a traumatic event or its circumstances, re-enacting the event or putting oneself in situations where the event is likely to happen again. This repetition is intended to achieve 'retrospective mastery'. In the case of traumatic memory, repetitive compulsive behaviour accounts for the return of the traumatic event after a period of time in the form of flashbacks and nightmares. However, the unavailability of memory together with the literal return of the traumatic experience refers to the central paradox of trauma, which is that - there is 'simultaneously too little and too much memory of the event.'

36 Theresa Betancourt 'Past horrors, present struggles', 2010, 13, "for instance, a former child soldier who displays hostility may be more likely to be negatively stereotyped and discriminated against compared to a former child soldier who does not display hostility."

37 Jason Stearns et al. "The national army and armed groups in the eastern Congo Untangling the Gordian knot of Insecurity", Usalama Project, Rift Valley Institute, 2013 1-66, "The reintegration stage was especially difficult: it targeted individual combatants and in the communities to which they returned the perception tended to be that those who took up arms were rewarded financially and given vocational training."

Pablo de Greiff, Establishing Links between DDR and Reparations, International Center for Transitional Justice Research Brief, February 2010, 1, https://www.ictj.org/sites/default/files/ ICTJ-DDR-Reparations-ResearchBrief-2010-English.pdf. 
The armed conflict in DRC has been coined by organisations such as the International Rescue Committee 'as the deadliest war in the world since World War II and the deadliest in Africa ever recorded. ${ }^{38}$ The repercussions of the conflict have been particularly grave for children with over 800,000 reported displaced persons, ${ }^{39}$ and an aggravating nutrition crisis and food insecurity impacting more than 400,000 children. ${ }^{40}$ Given the lack of sustained community interactions and follow-up programming - both in terms of psycho-social assistance and developmental aid - , any assistance to former child soldiers potentially creates a climate of competing victimhood between the experiences of child soldiers and other children impacted by the post-conflict, developmental challenges faced by the country. In fact, reintegration assistance to child soldiers has often been viewed as counterproductive, in that provisions that are otherwise expected to support and facilitate the process of reintegration risk generating community resentment. ${ }^{41}$

Going beyond some of the assumptions that guide the DDR programme, the question that must be asked concerns not only about 'how' reintegration is to be achieved, but also about 'what' are former child soldiers reintegrated 'to'? While a 'tick-box' approach most likely may regard the implementation of vocational and skills training as a reflection of best practice, in the absence of well-instituted economic opportunities or job market, the efficacy of holistic reintegration remains a hollow promise for most child soldiers. Similarly, the assumption around an existing, rather stable 'home community' where children may be reintegrated into remains equally problematic in the context of protracted conflicts experienced within DRC, since there are several communities that continue to survive in situations of non-permanent settlements and mass-scale displacement. ${ }^{42}$

\section{LACK OF 'FOLLOW UP', RECRUITMENT AND RE-RECRUITMENT}

As previously noted, the DDR programme in DRC experienced an operational delay in executing reintegration activities. Given that reintegration - both in terms of transition to a civilian life and re-settlement in the community - is a long-term endeavour, efforts in following-up equally require sustainable measures and practices. The program identified specific 'Community Protection Networks' - volunteer officials elected at the community level

38 WATCHLIST on Children and Armed Conflict, "Struggling to Survive: Children in Armed Conflict in the Democratic Republic of the Congo", April 2006: 1-8, https://www.womensrefugeecommission. org/gbv/resources/document/download/502.

39 Humanitarian Aid, "Restive eastern DR Congo home to one of world's worst displacement crises for children - UNICEF”, UN News, January 25, 2017, https://news.un.org/en/story/2018/01/1001211.

40 United Nations, “New Year could bring more misery to children in DR Congo's restive Kasai region, warns UNICEF", December 12, 2017, https://news.un.org/en/story/2017/12/639132-new-year-couldbring-more-misery-children-dr-congos-restive-kasai-region-warns.

41 Katharin Hermenau, et al., "Growing up in armed groups”, 2013.

42 Anna Maedl, et al. "Psychological Rehabilitation of Ex-combatants", 2010, 200. 
as well as identification of local organisations selected by the network, 'to undertake follow-up actions at the individual level.' ${ }^{43}$

\section{In fact, reintegration assistance to child soldiers has often been viewed as counterproductive, in that provisions that are otherwise expected to support and facilitate the process of reintegration risk generating community resentment. ${ }^{41}$}

Yet, the follow-up mechanisms were inadequate. First, there was a lack of mental health assessment in the follow-up measures. ${ }^{44}$ As a result, the psycho-social foundations of coping challenges and impact assessment of reintegration measures, as in family reunification, community sensitisation, economic and social activities, were side-lined. Second, the mandate of these measures was not clearly defined. Here again, reliable data on performance indicators - such as 'children's progress in reintegration', functioning of community mediation in mitigating possible disruptions, or the number and reasons for children who abandon the process (also called 'defaulters') were not clearly identified. ${ }^{45}$

In the absence of holistic documentation and processes of follow-up, the efficacy (and possible redundancy) of instituting reintegration activities became apparent. A tussle ensues between the fixed temporal dimension of a DDR programme, guided by the timed-framework of donor priorities and the long-drawn out, process-based experience of reintegration, largely impacting the scope of follow-up measures. For example, it is unclear whether children, who defaulted from the phase of reintegration at a time when they were over the age of 18 years, fall within the scope of the DDR programme and its follow-up measures. ${ }^{46} \mathrm{In}$ other instances, ambiguities prevailed regarding children who were re-recruited into armed forces following the completion of reintegration and family reunification.

Given these ambiguities, re-designing measures of reintegration continued to be based on unstructured feedback and the high probability of re-recruitment of former child soldiers.

43 DAl "Independent Evaluation of Special Projects", 22.

Beth Verhey, "Going Home", 2003, 54, "In addition, for demobilised children, a local organisation is selected by the community network to undertake follow-up actions at the individual level. This includes follow-up visits and micro-projects such as literacy classes, livestock, or small-scale vocational training."

44 Anna Maedl, et al. "Psychological Rehabilitation of Ex-combatants", 2010, 190.

45 DAl "Independent Evaluation of Special Projects", 24.

46 Beth Verhey, "Going Home", 2003, 55, "A review of the data shows that 62 per cent of those re-recruited were over 18 years of age. While forcible recruitment should be denounced at any age, for practical reasons, following up such cases is beyond the scope of activities for child protection organisations." 
In fact, DDR programmes instituted in a climate of competing victimhood also meant that certain reintegration activities, such as provision of reintegration kits and monetary payments to former child soldiers became an incentive for other conflict-affected children to enlist into armed groups ${ }^{47}$ In the specific context of DRC, re-recruitment was triggered by prolonged economic and social dependency, wherein engagement with 'violence came to be seen as a means to get access to resources, wealth and prestige. ${ }^{48}$ The question then is, what does reintegration, or a potential route 'away from violence' offer.

\section{PSYCHO-SOCIAL ROOTS OF REINTEGRATION: THE GAP BETWEEN INDIVIDUAL 'WAR EXPOSURE' AND 'POST-CONFLICT' COMMUNITY ADJUSTMENT}

The goal of reintegrating former child soldiers was largely undertaken through the 'Special Projects' within the overall DDR framework for the region. Reintegration was conceptualised broadly through micro-level economic and social activities. As indicated before, economic reintegration was conceptualised through provision of vocational skills-training and reintegration kits with monetary support. In terms of social activities, reintegration of child soldiers was executed through family reunification and school education. ${ }^{49}$ The measurement of success for economic and social reintegration could be contested in the absence of job opportunities and resistance from community members, respectively:

\section{...for a victim of rape or a 'girl mother', learning embroidery or sewing does not protect her (or other girls) from the same abuse; or, for a street child or demobilised child soldier, learning carpentry does not necessarily protect him from re-recruitment or prevent recruitment violations of other children... ${ }^{50}$}

Clearly, the tick-box approach does not correspond to reintegration 'as an experience', in that both economic, and social re-adjustment, are guided by, and dependent on, the child's psycho-social adjustment. Arguably, this form of psycho-social adjustment is closely tied to:

a. exposure to war trauma at an individual-level, and

b. post-conflict association with community stigma at an interactional-level.

47 Beth Verhey, "Going Home”, 2003, 55, “...in North and South Kivu, especially in a context of ongoing conflict, monetary payments in child soldier DDR efforts are not recommended. In the context of widespread poverty and vulnerability, such payments risk favouring child soldiers at the expense of other conflict-affected children and risk expanding recruitment or re-recruitment."

48 Sara Geenen, "Former combatants at the crossing: How to assess the reintegration of former combatants in the security and development nexus? Case study: Ruyigi (Burundi) and Kinshasa (DRC)", Dissertation, University of Antwerp, 2007, 1-21.

49 Nduwimana, "Reintegration of Child Soldiers”, 15.

50 Beth Verhey, “Going Home”, 2003, 17. 
In examining former child soldiers' experiences, Betancourt explains the 'disconnect' between an individual's war trauma and psycho-social reintegration that negates the post-conflict community interactions. ${ }^{51}$ The disconnect exists primarily because traumatic experiences of former child soldiers are assessed largely in relation to their wartime experiences and isolated from the everyday post-conflict stigma; while the latter is routinely lived through inter-personal exchanges with other members of the community. Betancourt's study on 'stigma' not only bridges the gap between individual trauma and psycho-social reintegration and re-adjustment; it also broadens our understanding of trauma from 'isolated events of the past' to a reality lived through a 'spectrum' of events continuing from the past and reflected in present interactions. From the point of view of the DDR, reintegration is far from being a 'clear break with the past'. Consequently, it can be inferred that failure to address the psycho-social foundations of economic and social reintegration remains at the core of a 'misdirected' intervention.

\section{PSYCHOLOGICAL MALFUNCTIONING AND BREAKDOWN}

Social learning theories understand behaviour as a learned phenomenon that is guided by an individual's observation within the environment. They explain the likelihood for a continued performance of behaviour based on the response received from the environment, in the form of rewards and punishment. ${ }^{52}$

From the point of view of understanding violence, social learning theories adapt to the experiences of child soldiers. In fact, various practices, such as dehumanisation and rewarding violent acts, ensure that child soldiers resort to atrocity performance not only as an assigned task but as an internalised behaviour that inclines them to the use of violence. Also referred to as the 'brutalisation' strategy, child soldiers are subjected to the risks of being habituated to the use of violence. As a result, the process of indoctrination not only damages children's pre-existing norms and values; it also involves instilling child recruits with 'new moral and social values that legitimise and celebrate violence. ${ }^{53}$

Drawn from these approaches, 'cultures of violence' can refer to individual combatants' sustained use of violence. ${ }^{54}$ These individuals are not only desensitised to violence, but the exposure propels its reinforcement as a socially-learned behaviour, thereby losing its negative value. When violence becomes the basis for further social interaction, it contributes to

51 Theresa Betancourt "Past horrors, present struggles", 2010.

52 Albert Bandura, "Social Learning Theory", 1971.

53 Kieran Mitton, "Rebels in a Rotten State: Understanding Atrocity in the Sierra Leone Civil War", Hurst and Company, October 2015, 228-231 [hereinafter Kieran Mitton, Rebels in a Rotten State, 2015]. 
further escalation and in a vicious logic, contributes to the very culture the interaction was embedded in..$^{55}$

In the experiences of child soldiers, exposure to large-scale violence distorts their pre-existing and fundamental belief system concerning 'safety, trust, self-esteem' to name a few. ${ }^{56}$ As perpetrators (even as victims and bystanders) of violence, their experience of mental trauma and shattered emotional-cognitive processing reaches to the extent of a 'psychological collapse'. This breakdown indicates a near-total removal of any psychological barriers that previously restrained violence. ${ }^{57}$ Equally, it translates into violence as a learned behaviour and basis for social interaction.

Part of the psychological breakdown develops, in former child soldiers, a response in terms of certain psychological defences. In the absence of the usual 'fight or flight' response options, child soldiers develop alternatives. ${ }^{58}$ Such defences range from active disassociation from the memory to 'repetition-compulsion' in the very pursuit of clarifying the memory, as indicated before. Equally, the removal of inhibitions vis-à-vis violence can in part account for child soldiers' re-recruitment in armed groups.

In DRC, a former child soldier recalled committing rapes of as many as 53 women, not driven by anger or aggression, but 'because it gave (them) a lot of pleasure ${ }^{59}$ This form of appetitive aggression has been documented in studies concerning child soldiers in DRC, such that 'a gradual transformation in the perception of violence is marked less by reactive aggression and more by an appetite for violence-related pleasure or enjoyment'. ${ }^{60}$

Thus, from the point of view of reintegration, exposure to violence and war-related trauma for a sustained period contributes to complex psychological malfunctioning of child soldiers, which impair their 'ability to work, contribute to income generation, to establish and sustain social relationships, or to take care of themselves. ${ }^{61}$ Thus, in such conditions, provision of economic and social re-integrative opportunities without engaging with their foundational psycho-social needs of the child may constitute what has previously been termed as a misdirected intervention.

55 Kieran Mitton, Rebels in a Rotten State, 2015, 50.

56 Anna Maedl, et al. "Psychological Rehabilitation of Ex-combatants", 2010, 187.

57 Kieran Mitton, Rebels in a Rotten State, 2015, 51.

58 Elisabeth Schauer and Thomas Elbert, "The Psychological Impact", 334.

59 Pete Jones, "Congo: We did whatever we wanted, says soldier who raped 53 women", April 11, 2013, The Guardian, https://www.theguardian.com/world/2013/apr/11/congo-rapes-g8-soldier.

60 Katharin Hermenau, et al., "Growing up in armed groups", 2013.

61 Anna Maedl, et al. "Psychological Rehabilitation of Ex-combatants", 2010, 178. 


\section{POST-CONFLICT EXPERIENCES AND COMMUNITY REINTEGRATION}

It would be a simplistic deduction to assume that the lives of children as former members of the armed group had been entirely 'negative'. Studies documenting the experiences of child soldiers reveal that membership in an armed group simultaneously provided them with positive association, group belonging and identification as well as triggers for psychological harm at different points of time. A denial of these complex layers of experiences may only account to some form of 'cognitive distortion'. ${ }^{62}$ Similarly, assuming a homogenous experience of community reintegration for former child soldiers as a 'favourable or positive experience' ignores the grey areas of children's needs within the DDR framework. Mogapi notes that very often, communities 'struggle to understand children's anger outbursts, problems with trusting, social withdrawal and other phenomena. ${ }^{63}$ Failing to understand some of the psychological experiences described previously, community members may inadvertently result in labelling and alienation instead of long-term reintegration of child soldiers. ${ }^{64}$ As mentioned before, reintegration as a short-term objective may be counterproductive to the well-being of young females due to the community fears around demobilised girls being a 'source of HIV/STI', possessing 'aggressive, or military mentality', or having a tendency of inciting deviant or promiscuous behaviour' among other stigmatising perceptions. ${ }^{65}$

\section{CONCLUSION: A PSYCHO-SOCIAL APPROACH TO REINTEGRATION OF CHILD SOLDIERS}

Long-term reintegration of former child soldiers in DRC requires innovation in existing DDR programmes. First, the processes involved in reintegration cannot assume a linear progression, in that the economic and social activities cannot disassociate from repairing the psycho-social harms faced by child soldiers. A dynamic framework equally calls for an integrated approach, with a long-term outlook and sustainable measures that allow for a community ownership of the reintegration process.

It has been noted that individual mental dispositions and responses to war-related trauma can hinder the process of holistic social reintegration and fuel reasons for re-recruitment of child soldiers. Alternatively, a psycho-social approach to reintegration in the DDR programme would combine the needs of children's 'individual psyche', along with their 'social ecology' and

\footnotetext{
62 Anna Maedl, et al. "Psychological Rehabilitation of Ex-combatants", 2010, 187.

63 Nomfundo Mogapi, "Reintegration of soldiers: The missing piece”, Intervention, Vol.2 No.3, (2004, 221-23) https://www.interventionjournal.com/sites/default/files/221_225_Mogapi.pdf.

64 Nomfundo Mogapi, "Reintegration of soldiers”, 223.

65 WATCHLIST on Children and Armed Conflict, "Struggling to Survive", 48.
} 
practices that bear 'cultural relevance. ${ }^{66}$ This is because reintegration is a two-way interaction, involving the return of a child and the community's role in 'receiving returnees. ${ }^{67}$

Traditional approaches to reintegration are guided by community practices and rituals which have often proved to hold therapeutic meaning both for the individual children as well as seemingly more identifiable for the other members. Some of these rituals include cleansing or purification rituals symbolic of treating an ex-combatant, development of collective social perceptions of 'personhood', and finally, the practices of seeking forgiveness for the past wrongdoings. ${ }^{68}$

In the future, the reintegration component of DDR must be drawn more thoroughly from contextual needs and be closely tied to individual and community reparations. ${ }^{69}$ As a safeguard against community backlash and competing victimhood, these linkages allow for incorporating the receiving communities' attitudes and reactions in decisions concerning determination of beneficiaries, addressing individual and collective psycho-social harms and in proposing sustainable and long-term reintegration measures for former child soldiers.

Arpita Mitra is a double master's degree graduate in Transitional Justice, Human Rights and the Rule of Law from the Geneva Academy, and Criminology and Criminal Justice from the University of Oxford. Through her research, she specialises in the legal and psycho-social protection of children in armed conflict, post-conflict, and situations of displacement. She has previously assisted the UNDP-IAWG on the Disarmament, Demobilisation and Reintegration (DDR) based in Geneva, and contributed to the UN Special Rapporteur's mandate on the human rights of Internally Displaced Persons. All views expressed in this article are hers alone and do not represent the views of her employer.

66 Katherine Stott, "Out of sight, out of mind? The psychosocial needs of children formerly associated with armed forces: A case study of Save the Children UK's work in Beni and Lubero territories, North Kivu province, Democratic Republic of Congo", International Journal of Health Planning and Management, 2009, S52-60, https://onlinelibrary.wiley.com/doi/pdf/10.1002/hpm.1022.

67 Nduwimana, "Reintegration of Child Soldiers", 5.

68 Brian Engdahl et al. Psychosocial interventions with former combatants", in Green B, et al (Eds), 2003, 271-84.

69 Pablo de Greiff, "Establishing Links between DDR and Reparations", 1-4. 